\title{
Qualidade do melão ‘Orange Flesh' minimamente processado armazenado sob atmosfera modificada
}

\author{
Quality of the fresh cut 'Orange Flesh' melon stored \\ under modified atmosphere
}

\author{
Rogério Lopes Vieites ${ }^{1 *}$; Regina Marta Evangelista ${ }^{1}$; Luciana Costa Lima ${ }^{1}$; \\ Maria Rosa de Moraes ${ }^{1}$; Leandro Camargo Neves ${ }^{2}$
}

\begin{abstract}
Resumo
Este trabalho teve como objetivo avaliar o efeito da atmosfera modificada na qualidade do melão 'Orange Flesh'minimamente processado. Os cubos de melões foram sanificados com $100 \mathrm{mg} \mathrm{L}^{-1}$ de hipoclorito de sódio por um minuto, lavados, drenados e embalados com diferentes concentrações de $\mathrm{O}_{2}$ e $\mathrm{CO}_{2} \mathrm{em}$ sacos plásticos de polietileno (Nylon Poli). Foram avaliados a cada dois dias durante dez dias quanto a firmeza, pectina total, pectina solúvel e atividade da polifenoloxidase e peroxidase. Ao final do período de conservação, os produtos vegetais com modificação da atmosfera mantiveram a textura mais firme e a concentração de $5 \% \mathrm{O}_{2}+3 \% \mathrm{CO}_{2}$ apresentaram menor teor de pectina total e juntamente com a concentração de $100 \% \mathrm{~N}_{2}$ o menor teor de pectina solúvel e não apresentaram atividades de polifenoloxidase e peroxidase.
\end{abstract}

Palavras-chave: Cucumis melo L, conservação, mistura gasosa, processamento mínimo

\begin{abstract}
This work aimed at evaluate the effect of the fresh cut 'Orange Flesh' melon stored under modified atmosphere. The cubes of melons were sanitizationed with $100 \mathrm{mg} \mathrm{L}-1$ of hypoclorite of sodium for one minute, washed, drained and wrapped with different concentrations of $\mathrm{O}_{2}$ and $\mathrm{CO}_{2}$ in plastic bags of polyethylene (Nylon Polished). They were appraised every other day for ten days as regards the firmness, total pectin, soluble pectin and activity of the polifenoloxidase and peroxidase. At the end of the conservation period, it was verified that melons sustained the firmest texture of the vegetable products under modified atmosphere, and the concentration of $5 \% \mathrm{O}_{2}+3 \% \mathrm{CO}_{2}$ showed smaller content of total pectin and together with the concentration of $100 \% \mathrm{~N}_{2}$ the smallest content of soluble pectin, the polifenoloxidase activity was not verified as well as of the peroxidase.
\end{abstract}

Key words: Cucumis melon L, conservation, gaseous mixtures, fresh cut

1 Universidade Estadual Paulista (UNESP), Faculdade de Ciências Agronômicas, Departamento de Gestão e Tecnologia Agroindustrial, Botucatu, SP. vieites@fca.unesp.br

2 Universidade Federal de Roraima (UFRR/CCA), Departamento de Fitotecnia, BR 174, Km 12, Campus Cauamé, CEP 69310270, Boa Vista/RR.

* Autor para correspondência. 


\section{Introdução}

As substâncias pécticas são derivadas de ácidos poligalacturônicos e ocorrem na forma de protopectina, ácidos pécticos, pectina e ácidos pectínicos (SALUNKHE et al., 1991). São caracterizadas por diferentes solubilidades, dependendo do estádio de maturação do fruto (ABREU, 1995). Quando os grupos carboxílicos encontram-se ligados ao cálcio, formam o pectato de cálcio, que é insolúvel e denominado de protopectina que é predominante nos tecidos de frutos imaturos. Com a maturação, há liberação de cálcio e solubilização da protopectina da parede celular. Há, então, modificação na textura, que se torna gradualmente macia (CHITARRA; CHITARRA, 1990).

O melão (Cucumis melo L.) é uma espécie polimórfica, cujas formas botânicas diferenciam-se quanto aos aspectos de sensibilidade ao frio, capacidade de conservação, atividade metabólica e, sobretudo em forma, tamanho de fruto e estrutura da casca e da polpa. A casca apresenta variação de coloração que vai desde o laranja escuro até branco e verde, em função da cultivar (ARTÉS et al., 1993; MENEZES, 1996).

As mudanças na estrutura da maioria dos frutos têm sido atribuídas à ação de poligalacturonases (PG) e pectinametilesterases (PME). A endoenzima PG, que é encontrada na maioria dos frutos, catalisa a hidrólise das ligações a 1,4 do ácido poligalacturônico. Esta enzima é classificada em dois grupos, com base na sua ação sobre o substrato: a endo-PG, com típico rompimento aleatório das ligações glicosídicas e a exo-PG, com rompimento terminal (AWAD, 1993).

A PME é outra enzima importante na perda de firmeza dos frutos, pois promove a eliminação dos grupos metoxílicos da molécula de pectina e nem sempre está presente nos frutos que contém pectina (AWAD, 1993; LIMA, 1999). A PME e a PG são enzimas capazes de degradar as substâncias pécticas encontradas na parede celular e na lamela média e não têm apresentado atividades substanciais durante o armazenamento do melão (LESTER; DUNLAP, 1985).

A degradação das substâncias pécticas está correlacionada com a perda de firmeza da polpa dos frutos. A hidrólise de carboidratos poliméricos, especialmente, substâncias pécticas e hemicelulose, enfraquece a parede celular e a força coesiva que liga as células. Em estádio inicial de degradação, a textura se torna mais palatável, porém com o decorrer acontece uma desintegração das estruturas do fruto (WILLS et al., 1998).

$\mathrm{O}$ mecanismo que controla o amaciamento em melão não tem sido claramente definido. Mccollum et al., (1989) e Holland (1993) relacionaram a perda de firmeza à modificação de polissacarídeos hemicelulósicos e pécticos, com perda de açúcares neutros não celulósicos. BLEINROTH (1994) cita que a firmeza da polpa do melão é dada pela protopectina, composto péctico, parcialmente insolúvel, localizado na lamela média das células adjacentes e na parede primária, sendo que à medida que o amadurecimento avança a protopectina vai sendo convertida em compostos solúveis levando a um amaciamento dos tecidos. PORTELA; CANTWELL, (1998) relataram que a firmeza média de melões minimamente processados diminui de 17,5 $\mathrm{N}$ para 7,3 N com o armazenamento por 12 dias. De acordo com Madrid; Cantwell (1993), a firmeza dos melões minimamente processados diminuiu 50\% durante o armazenamento, a $5^{\circ} \mathrm{C}$ por 8 dias.

Enquanto as hidrolases são responsáveis pela perda de firmeza das frutas e hortaliças minimamente processadas (WILEY, 1994), as enzimas peroxidase e polifenoloxidase são responsáveis pelo escurecimento do tecido vegetal (DAREZZO, 2000). $\mathrm{O}$ escurecimento em resposta a injúrias físicas e fisiológicas é devido à oxidação de fenólicos. O colapso celular promove contato dos fenólicos presentes com enzimas associadas ao escurecimento, como as polifenoloxidases (VILAS BOAS, 1999).

A mudança nos padrões de consumo de alimentos tem levado ao maior consumo de frutas e hortaliças em detrimento dos produtos industrializados. Ao mesmo tempo, os consumidores desejam produtos com qualidade e praticidade. Nesse sentido, a demanda por frutas e hortaliças minimamente processadas tem evoluído rapidamente (BURNS, 1995; SANTOS, 2003). 
A atmosfera modificada pode ser criada de forma passiva ou ativa. No caso da atmosfera modificada passiva, o produto é acondicionado em embalagem e a atmosfera é modificada pela própria respiração do produto. A atmosfera modificada ativa é criada injetando-se no espaço livre da embalagem uma mistura gasosa pré-determinada (YAM; LEE, 1995; CHITARRA, 1998). Uma das vantagens da atmosfera modificada ativa é permitir a rápida estabilização da atmosfera desejada (ZAGORY; KADER, 1988), porém, a atmosfera final, dentro da embalagem, é semelhante nos dois processos.

Kader; Ke (1994) observaram que o mínimo de $\mathrm{O}_{2}$ e máximo de $\mathrm{CO}_{2}$ tolerado pelo melão Cantaloupe é de $2 \%$ e $15 \%$, respectivamente.

Portela; Cantwell, (1998) observaram que pedaços de melões Honeydew armazenados sob refrigeração e atmosfera modificada $\left(15 \%\right.$ de $\left.\mathrm{CO}_{2}\right)$ apresentaram boa a muito boa qualidade visual total, respectivamente, até o $6^{\circ}$ dia de armazenamento. O decréscimo na qualidade foi devido à alteração da aparência de produto fresco, com pequeno ressecamento da superfície.

O presente trabalho teve como objetivo avaliar a qualidade do melão 'Orange Flesh' minimamente processado conservado sob diferentes atmosferas modificadas.

\section{Material}

Foram utilizados melões tipo Orange Flesh classe 6 (6 frutos/caixa) com aproximadamente $1,5 \mathrm{~kg}$ cada fruto. Os frutos foram adquiridos em Mossoró - RN, transportados até ao CEAGESP - SP onde foram recepcionados e novamente transportados ao Laboratório de Frutas e Hortaliças do Departamento de Produção Vegetal da Universidade Estadual Paulista "Júlio de Mesquita Filho", Campus de Botucatu -SP, onde foram conduzidos o experimento.

\section{Métodos}

\section{Beneficiamento}

Após seleção quanto à uniformidade de maturação em função da coloração da casca, tamanho e ausência de injúrias, os frutos foram lavados com água e detergente neutro; em seguida os frutos foram pré-resfriados a $10^{\circ} \mathrm{C}$ por 24 horas antes do processamento mínimo.

Após o pré-resfriamento, os frutos foram processados em cubos e sanificados com $100 \mathrm{mg} \mathrm{L}^{-1}$ de hipoclorito de sódio por um minuto de imersão, a $20^{\circ} \mathrm{C}$.

\section{Experimentos}

Melões minimamente processados em cubos foram submetidos a atmosferas modificadas ativas com diferentes concentrações de $\mathrm{O}_{2}$ e $\mathrm{CO}_{2}$. Foram utilizados como embalagens os sacos plásticos de polietileno transparente, denominados 'Nylon Poli', os quais são caracterizados como alta barreira ao oxigênio $\left(10 \mathrm{~cm}^{3} \mathrm{dia}^{-1}\right)$ e ao vapor d'água $\left(5 \mathrm{~m}^{2} \mathrm{dia}^{-1}\right)$, com dimensões $15 \times 22 \mathrm{~cm}$. As atmosferas testadas foram: Testemunha - embalagem apenas selada (atmosfera modificada passivamente); vácuo parcial - retirada da atmosfera dos sacos plásticos; $100 \%$ $\mathrm{N}_{2}$ - injeção de $100 \%$ de $\mathrm{N}_{2} ; 5 \% \mathrm{O}_{2}+1 \% \mathrm{CO}_{2}$ injeção de $5 \%$ de $\mathrm{O}_{2}$ e $1 \%$ de $\mathrm{CO}_{2} ; 5 \% \mathrm{O}_{2}+3 \%$ $\mathrm{CO}_{2}$ - injeção de $5 \%$ de $\mathrm{O}_{2}$ e $3 \%$ de $\mathrm{CO}_{2}$.

\section{Técnicas analíticas}

O tratamento testemunha foi representado por frutos embalados em atmosfera passiva (sem injeção de $\mathrm{O}_{2} \mathrm{e}$ $\mathrm{CO}_{2}$ ) realizando-se apenas a selagem das embalagens. Na obtenção do vácuo parcial, foi efetuado o vácuo por cinco segundos e posterior selagem das embalagens. Nas atmosferas ativas, além do vácuo, foi efetuado a injeção das atmosferas desejadas e selagem das embalagens utilizando-se Seladora a vácuo Tec Maq modelo AP 500. Após os tratamentos, os produtos foram armazenados sob refrigeração $\left(5 \pm 1^{\circ} \mathrm{C}\right.$ e $85 \pm 5 \%$ de UR) por 10 dias, sendo avaliados a cada 2 dias quanto a Firmeza $\left(\mathrm{gf} / \mathrm{cm}^{2}\right)$ - medida nos cortes, utilizando-se Texturômetro Stevens - LFRA Texture Analyser, com ponta de prova - TA 9/1000 e velocidade de penetração de 2,0 $\mathrm{mm} \mathrm{seg}^{-1}$, até a profundidade de 2,0 mm, Pectina total (PT) e pectina solúvel (PS) (mg de ácido 
galacturônico $100 \mathrm{~g}^{-1}$ de polpa) - o teor de pectinas, total e solúvel, foram determinadas segundo a técnica descrita por Mccready; Mccomb (1952) e quantificadas colorimetricamente segundo Bitter; Muir (1962). A atividade das enzimas polifenoloxidase e peroxidase foram medidas de acordo com o método desenvolvido por Flurkey; Jen (1978) e as atividades da polifenoloxidase e da peroxidase foram expressas em UE minuto ${ }^{-1} \mathrm{~g}^{-1}$ de polpa.

\section{Delineamento experimental}

O delineamento experimental utilizado foi o inteiramente casualizado, fatorial. $5 \times 6$ ( 5 concentrações de $\mathrm{O}_{2}$ e $\mathrm{CO}_{2}$ e 6 tempos de armazenamento: 0, 2, 4, 6, 8 e 10 dias). Foram utilizadas 3 repetições, sendo cada repetição composta por uma bandeja. Os dados foram analisados pelo programa SISVAR segundo Ferreira, (1998) sendo as médias dos tratamentos e as interação (tratamentos $\mathrm{x}$ tempo), comparadas utilizando-se teste de Tukey a $5 \%$ de probabilidade e o efeito de fator tempo por regressão (GOMES, 1987).

\section{Resultados e Discussão}

As variações na firmeza dos melões minimamente processados foram significativas para as concentrações de $\mathrm{O}_{2}$ e $\mathrm{CO}_{2}$ e tempo de armazenamento, porém separadamente $(\mathrm{P}<0,05)$. Houve diferença entre os frutos do tratamento testemunha e os sob injeção de $100 \%$ de $\mathrm{N}_{2}$ (Tabela 1).

Com o tempo de armazenamento, ocorreu redução da firmeza do início ao final do experimento (Figura 1). Os frutos apresentaram redução média de $42 \%$ em sua firmeza. Melões Honeydew também perderam firmeza quando armazenados a $5^{\circ} \mathrm{C}$ em atmosfera com $15 \%$ de $\mathrm{CO}_{2}$ (PORTELA; CANTWELL, 1998).

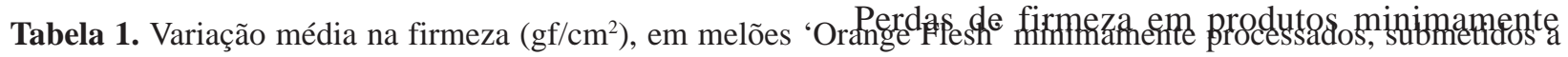
diferentes concentrações de $\mathrm{O}_{2}$ e $\mathrm{CO}_{2}$ e armazenados a $5 \pm 1^{\circ} \mathrm{C}$ e $85 \pm 5 \%$ de UR por 10 dias.

\begin{tabular}{cc}
\hline Tratamentos & Firmeza \\
\hline Testemunha & $50,22 \mathrm{a}$ \\
Vácuo parcial & $54,11 \mathrm{ab}$ \\
$100 \% \mathrm{~N}_{2}$ & $57,56 \mathrm{~b}$ \\
$5 \% \mathrm{O}_{2}+1 \% \mathrm{CO}_{2}$ & $56,72 \mathrm{ab}$ \\
$5 \% \mathrm{O}_{2}+3 \% \mathrm{CO}_{2}$ & $53,94 \mathrm{ab}$ \\
\hline $\mathrm{CV} \%$ & 13,12 \\
\hline
\end{tabular}

Médias seguidas pela mesma letra não diferem significativamente entre si, a 5\% de probabilidade, pelo teste de Tukey.

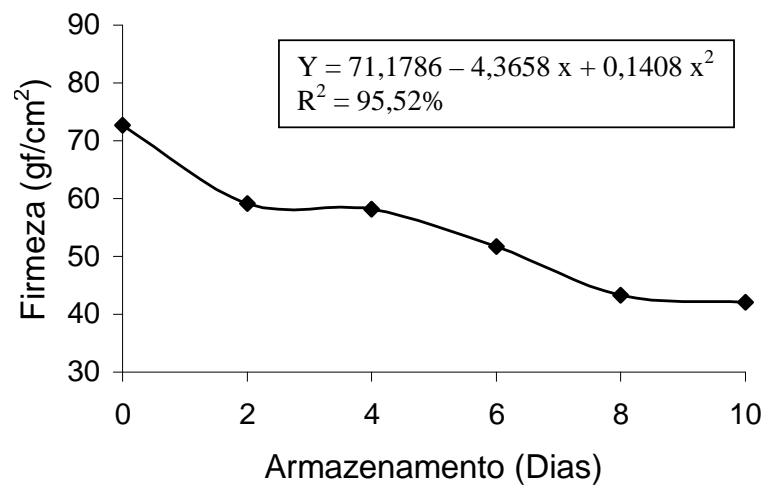

Figura 1. Variação média na firmeza $\left(\mathrm{gf} / \mathrm{cm}^{2}\right)$, em melões 'Orange Flesh' minimamente processados, submetidos a diferentes concentrações de $\mathrm{O}_{2}$ e $\mathrm{CO}_{2}$ e armazenados a $5 \pm 1^{\circ} \mathrm{C}$ e $85 \pm 5 \%$ de UR por 10 dias. 
processados nem sempre correlacionam-se com o aumento dos níveis de PME e PG. Experimentos têm tentado correlacionar o amaciamento com a despolimerização de polissacarídeos por hidrolases associadas a parede celular. Redução no peso molecular da fração de polissacarídeos pécticos, acompanhada pela perda de resíduos galactosil e arabinosil tem, inúmeras vezes, acompanhado o amaciamento em frutos (REDGWELL; FISCHER, 2002). Melões Honeydew também perderam firmeza quando armazenados a $5^{\circ} \mathrm{C}$ em atmosfera com $15 \%$ de $\mathrm{CO}_{2}$ (PORTELA; CANTWELL, 1998).

Sigrist (1992) relatou que o amolecimento dos frutos pode ser causado pela transpiração, que comprometeu o produto provocando perda qualitativa e quantitativa. Para Awad (1993) e Chitarra; Chitarra (1985), além do fator transpiração, a decomposição enzimática da parede celular e lamela média também pode ser responsável por alterações na textura dos frutos no período pós-colheita.
Os fatores concentrações de $\mathrm{O}_{2}$ e $\mathrm{CO}_{2}$ e tempo de armazenamento afetaram interativamente as variáveis PT e PS $(\mathrm{P}<0,05)$. A pectina total apresentou diferenças significativas a partir do segundo dia de armazenamento quando os frutos sob vácuo parcial e sob atmosfera com 5\% $\mathrm{O}_{2}+3 \%$ $\mathrm{CO}_{2}$ diferiram dos demais (Tabela 2). Aos 4 dias, uma diferença foi observada entre os frutos sob injeção de $100 \%$ de $\mathrm{N}_{2}$ e sob atmosfera com $5 \% \mathrm{O}_{2}$ $+1 \% \mathrm{CO}_{2}$ e os frutos do tratamento testemunha. Aos 6 dias, nenhuma diferença foi observada, mas aos 8 dias de armazenamento os frutos sob atmosfera com $5 \% \mathrm{O}_{2}+1 \% \mathrm{CO}_{2}$ apresentaram o menor teor de PT e diferiram dos demais tratamentos que foram iguais entre si. Aos 10 dias, os frutos do tratamento testemunha e os frutos sob vácuo parcial foram iguais e diferiram dos frutos sob atmosfera com $5 \% \mathrm{O}_{2}+$ $1 \% \mathrm{CO}_{2}$ e posteriormente dos sob atmosfera com $5 \% \mathrm{O}_{2}+3 \% \mathrm{CO}_{2}$

Tabela 2. Variação média no teor de pectina total e solúvel ( $\mathrm{mg}$ de ácido galacturônico $100 \mathrm{~g}^{-1}$ de polpa), em melões minimamente processados, submetidos a diferentes concentrações de $\mathrm{O}_{2} \mathrm{e} \mathrm{CO}_{2} \mathrm{e}$ armazenados a $5 \pm 1^{\circ} \mathrm{Ce} 85 \pm 5 \%$ de UR por 10 dias.

\begin{tabular}{|c|c|c|c|c|c|c|}
\hline \multicolumn{7}{|c|}{ Dias de Armazenamento } \\
\hline Tratamentos & 0 & 2 & 4 & 6 & 8 & 10 \\
\hline \multicolumn{7}{|c|}{ Pectina total } \\
\hline Testemunha & $526,35 \mathrm{a}$ & $464,58 \mathrm{~b}$ & $348,86 \mathrm{bc}$ & $387,48 \mathrm{a}$ & $303,23 \mathrm{~b}$ & $438,81 \mathrm{c}$ \\
\hline Vácuo parcial & $526,35 \mathrm{a}$ & $346,58 \mathrm{a}$ & $288,74 \mathrm{ab}$ & $414,52 \mathrm{a}$ & $348,27 \mathrm{~b}$ & $430,78 \mathrm{c}$ \\
\hline $100 \% \mathrm{~N}_{2}$ & $526,35 \mathrm{a}$ & $481,95 \mathrm{~b}$ & 249,98 a & 403,43 a & $366,85 \mathrm{~b}$ & $393,21 \mathrm{bc}$ \\
\hline $5 \% \mathrm{O}_{2}+1 \% \mathrm{CO}_{2}$ & $526,35 \mathrm{a}$ & $496,95 \mathrm{~b}$ & $425,29 \mathrm{c}$ & $355,03 \mathrm{a}$ & $209,34 \mathrm{a}$ & $321,02 \mathrm{~b}$ \\
\hline $5 \% \mathrm{O}_{2}+3 \% \mathrm{CO}_{2}$ & $526,35 \mathrm{a}$ & $296,60 \mathrm{a}$ & $314,23 \mathrm{ab}$ & $426,26 \mathrm{a}$ & $299,24 \mathrm{~b}$ & $235,21 \mathrm{a}$ \\
\hline $\mathrm{CV}(\%)$ & 10,58 & & & & & \\
\hline \multicolumn{7}{|c|}{ Pectina solúvel } \\
\hline Testemunha & $59,96 \mathrm{a}$ & $83,15 \mathrm{~d}$ & $40,75 \mathrm{a}$ & $45,17 \mathrm{ab}$ & $75,10 \mathrm{~b}$ & $68,76 \mathrm{~b}$ \\
\hline Vácuo parcial & 59,96 a & $64,41 \mathrm{bc}$ & $56,56 \mathrm{~b}$ & 29,96 a & $74,18 \mathrm{~b}$ & $67,62 \mathrm{~b}$ \\
\hline $100 \% \mathrm{~N}_{2}$ & 59,96 a & $33,42 \mathrm{a}$ & $44,67 \mathrm{ab}$ & $49,35 \mathrm{~b}$ & $71,10 \mathrm{~b}$ & $48,65 \mathrm{a}$ \\
\hline $5 \% \mathrm{O}_{2}+1 \% \mathrm{CO}_{2}$ & 59,96 a & $66,23 \mathrm{c}$ & $55,00 \mathrm{ab}$ & $58,60 \mathrm{~b}$ & $52,82 \mathrm{a}$ & $71,14 \mathrm{~b}$ \\
\hline $5 \% \mathrm{O}_{2}+3 \% \mathrm{CO}_{2}$ & $59,96 \mathrm{a}$ & $50,47 \mathrm{~b}$ & $44,36 \mathrm{ab}$ & $53,40 \mathrm{~b}$ & $53,87 \mathrm{a}$ & $50,44 \mathrm{a}$ \\
\hline $\mathrm{CV}(\%)$ & 11,92 & & & & & \\
\hline
\end{tabular}

Médias seguidas pela mesma letra na coluna, não diferem significativamente entre si, a 5\% de probabilidade, pelo teste de Tukey.

Assim, foi observado que não houve um comportamento fixo para a variável PT, mas os frutos sob atmosfera com $5 \% \mathrm{O}_{2}+3 \% \mathrm{CO}_{2}$ determinaram menor teor de PT ao final do armazenamento de 10 dias.
Com o armazenamento, foi observado redução da PT em todos os tratamentos. MENEZES et al., (1995) verificaram estabilidade dos compostos pécticos durante o armazenamento de melão amarelo 'Agroflora 646'. Estes autores sugeriram que o 
amolecimento de melão pode estar relacionado com outros processos, tais como, a perda da integridade da membrana das células mesocárpicas e rompimento das interações iônicas entre polímeros da parede celular. LESTER; DUNLAP (1985) também não encontraram mudanças no conteúdo de pectina total durante o amadurecimento de melão.

A variável pectina solúvel apresentou diferenças significativas a partir do segundo dia de armazenamento quando diferenças foram observadas entre os frutos do tratamento testemunha e os demais. Aos 4 dias de armazenamento, a única diferença observada foi entre os frutos do tratamento testemunha e sob vácuo parcial, porém aos 6 dias, a diferença notada foi dos frutos sob vácuo parcial com os sob injeção de $100 \%$ de $\mathrm{N}_{2}$, sob atmosfera com $5 \% \mathrm{O}_{2}+1 \% \mathrm{CO}_{2}$ e sob atmosfera com $5 \% \mathrm{O}_{2}+3 \%$ $\mathrm{CO}_{2}$ que foram iguais entre si. Aos 8 dias de armazenamento, os frutos sob atmosferas com 5\% $\mathrm{O}_{2}+1 \% \mathrm{CO}_{2}$ e $5 \% \mathrm{O}_{2}+3 \% \mathrm{CO}_{2}$ foram iguais entre si e diferiram dos demais. Aos 10 dias, os frutos sob atmosfera com $5 \% \mathrm{O}_{2}+3 \% \mathrm{CO}_{2}$ se igualaram aos sob injeção de $100 \%$ de $\mathrm{N}_{2}$ e diferiram dos demais tratamentos.

Pelos dados observados, a pectina solúvel não apresentou comportamento fixo como ocorreu com a pectina total, mas os menores teor foram obtidos pelos frutos sob injeção de $100 \%$ de $\mathrm{N}_{2}$ juntamente com os sob atmosfera com $5 \% \mathrm{O}_{2}+3 \% \mathrm{CO}_{2}$ ao final do armazenamento.

Com o armazenamento, foi observado aumento do teor nos frutos do tratamento testemunha, sob vácuo parcial e sob atmosfera com $5 \% \mathrm{O}_{2}+1 \%$ $\mathrm{CO}_{2}$ e redução nos frutos sob injeção de $100 \%$ de $\mathrm{N}_{2}$ e sob atmosfera com $5 \% \mathrm{O}_{2}+3 \% \mathrm{CO}_{2}$.

Peroni (2002) verificando a influência do cloreto de cálcio em melão 'Amarelo' minimamente processado observou aumento linear da PS com o tempo de armazenamento. Mccollum et al., (1989) citaram que a PT permaneceu constante e as PS aumentaram durante o armazenamento de melões 'Galia'.
Desta forma, foi observado que não houve relação entre variável firmeza e variáveis PT e PS. Menezes (1996) indicou que a perda de firmeza durante o armazenamento não foi atribuído somente à despolimerização e solubilização de protopectina como sugere Bleinroth (1994), mas a hidrólise de outros componentes da parede celular.

O escurecimento de frutos em resposta a injúrias físicas e fisiológicas foi devido à oxidação de fenólicos. O colapso celular causa descompartimentalização que promove o contato dos fenólicos presentes com enzimas associadas ao escurecimento, como as polifenoloxidases.

Nesta investigação, não foram detectadas atividades da polifenoloxidase e peroxidase nos melões minimamente processados. Considerando que para a obtenção de produtos minimamente processados os mesmos devem estar em um ponto ideal de amadurecimento, $\log$ o a polifenoloxidase e peroxidase possam ter atuado antes ou durante o processamento mínimo.

Arruda (2002) verificou retenção do escurecimento da polpa do melão durante o armazenamento devido à baixa temperatura de armazenamento $\left(3^{\circ} \mathrm{C}\right)$ e citou que provavelmente a baixa temperatura reduziu a atividade das enzimas responsáveis pelo escurecimento enzimático. Lamikanra et al (2000) citaram que a modificação na coloração observada em melões Cantaloupe minimamente processado foi atribuída à oxidação de $\beta$ - caroteno e não a de compostos fenólicos.

\section{Conclusões}

Os produtos vegetais com modificação da atmosfera mantiveram a textura mais firme e a concentração de $5 \% \mathrm{O}_{2}+3 \% \mathrm{CO}_{2}$ apresentaram menor teor de pectina total e juntamente com a concentração de $100 \% \mathrm{~N}_{2}$ o menor teor de pectina solúvel e não apresentaram atividades de polifenoloxidase e peroxidase. 


\section{Referências}

ABREU, C.M.P. Efeito da embalagem de polietileno e da refrigeração no escurecimento interno e composição química durante a maturação do abacaxi cv. Smooth Cayenne. Lavras: UFLA, 1995. 94p. (Tese - Doutorado em Ciência dos Alimentos).

ARRUDA, M.C.de. Processamento mínimo de melão rendilhado: tipo de corte, temperatura de armazenamento e atmosfera modificada. Piracicaba: ESALq. (Dissertação de Mestrado em Agronomia). 2002, $71 \mathrm{p}$.

ARTÉS, F.; ESCRICHE, A. J.; MARTÍNEZ, J. A.; MARIN, J. G. Quality factors in four varieties of melon (Cucumis melo, L.). Journal of Food Quality, Trumbull, v. 16, n. 2, p. 91-100. Apr. 1993.

AWAD,M. Fisiologia pós-colheita de frutos. São Paulo: Nobel, 1993. 114p.

BITTER, T.; MUIR, H.M. A modified uronic acid carbazole reaction. Analytical Biochemistry, New York, v.34, p. 330334, 1962.

BLEINROTH, E.W. Determinação do ponto de colheita. In: GORGATTINETO, A.; GAYET, J.P.; BLEINROTH, E.W. et al. Melão para exportação: procedimentos de colheita e pós colheita. Brasília: Embrapa, Spi, 1994. p.11 21 (FRUPEX. Série Publicações Técnicas, 6).

BURNS, JK. Lightly processed fruits and vegetables: Introduction to the Colloquium. HortScience, Alexandria, v.30, n.1, p.14 17, feb, 1995.

CHITARRA, M.I.F. Processamento mínimo de frutos e hortaliças, Viçosa: UFV. 1998. 88p.

CHITARRA, M.I.F.; CHITARRA, A.B. Pós colheita de frutos e hortaliças: fisiologia e manuseio, Lavras: ESAL, Fundação de Apoio ao Ensino, Pesquisa e Extensão, 1985.293p.

CHITARRA, M.I.F; CHITARRA, A.B. Pós-colheita de frutos e hortaliças: fisiologia e manuseio, Lavras: ESAL/ FAEPE, 1990.320p.

DAREZZO, H.M. Processamento mínimo de alface (Lactuca sativa L.). In: ENCONTRO NACIONAL SOBRE PROCESSAMENTO MÍNIMO DE FRUTAS E HORTALIÇAS, 2., Viçosa, 2000. Palestras... Viçosa: Universidade Federal de Viçosa, 2000. p. 117124.

FERREIRA, D.N. Sistema de análise estatística para dados balanceados, Lavras: UFLA/DEX/SISVAR, 1998.

FLURKEY, W.H.; JEN, J.J. Peroxidase and polyfenol oxidase activities in developing peaches. Journal of Food Science, Chicago, v.6, n.43, p.1826-1831, nov/dec. 1978.
GOMES, F.P. Curso de estatística experimental, $12^{\mathrm{a}}$ edição Piracicaba: Nobel, 1987. 467 p.

HOLLAND, N. Conservação pós-colheita de pêssego (cv. Biut): interação entre cálcio e temperatura, Lavras, p.166, 1993. (Dissertação de Mestrado). Universidade Federal de Lavras, Lavras, MG.

KADER, A. A.; KE, D. Controlled atmospheres. In: PAULL, R. E.; ARMSTRONG, J. W. (Ed.) Insect pest and fresh horticultural products: treatments and responses. Wallingford: CAB International, 1994. p. 223-236.

LAMIKANRA, O.; WATSON, M.A. Cantaloupe melon peroxidase: Characterization and effects of additivies on activity. Journal of Agricultural and Food Chemistry, Nahrung, v.44, p. 168 172, 2002.

LAMIKANRA, O.; CHEN, J.C.; BANKS, D.; HUNTER, P.A. Biochemical and microbial changes during the storage of minimally processed Cantaloupe. Journal of Agricultural and Food Chemistry, Washington, v.48, n.12, p. 5955-5961. Dec. 2000.

LESTER, G.E.; DUNLAP, J.P. Physiological changes during development and ripening of 'Perlita' muskmelon fruits. Scientia Horticulturae, Amsterdam, v.26, p.323-331, 1985.

LIMA, L.C. Armazenamento de maçãs cv. Royal Gala sob refrigeração e atmosfera controlada. 1999, 96p. Dissertação (Mestrado em Ciência dos Alimentos) Universidade Federal de Lavras, Lavras, MG.

LIMA, L.C.O. Tecido esponjoso em manga 'Tommy Atkins': transformações químicas e bioquímicas no mesocarpo durante o armazenamento. Lavras: UFLA, 1997. 148p. (Tese - Doutorado em Ciência dos Alimentos) - Universidade Federal de Lavras, Lavras, MG.

MADRID, M.; CANTWELL, M.I. Use of high $\mathrm{CO}_{2}$ atmospheres to mantain quality of intact and fresh-cut melon. In: PROCEEDING $6^{\text {TH }}$ INTERNATIONAL CONTROLLED ATMOSPHERE RESEARCH CONFERENCE, NRAES, 71, Ithaca, NY, 1993, p. 736-745.

McCOLlUM, T.G.; HUBER, D.J.; CANTLIFFE, D.J. Modification of polyuronides and hemicelluloses during muskmelon fruit softening. Physiologia Plantarum, Copenhagen, v.76, p. 303-308, March, 1989.

McCREADY, P.M.; McCOOMB, E.A. Extration and determination of total pectin materials. Analytical Chemistry, Washington, v.24, n.12, p.1586-1888, 1952.

MENEZES, J.B. Qualidade pós-colheita de melão tipo "Gália" durante a maturação e o armazenamento. 1996. 164p. Tese (Doutorado em Ciência dos Alimentos)Universidade Federal de Lavras, Lavras, MG. 
MENEZES, J.B.; CHITARRA, A.B.; CHITARRA, M.I.F. Caracterização pós-colheita do melão amarelo 'Agroflora 646'. Horticultura Brasileira, v.13, n.2, p. 150-153, 1995.

PERONI, K.M. da C. Influência do cloreto de cálcio sobre a vida de prateleira de melão 'Amarelo' minimamente processado. 2002, 86p Dissertação (Mestrado em Ciência dos Alimentos) - Universidade Federal de Lavras, Lavras, MG.

PORTELA, S.I.; CANTWELL, M.I. Quality changes of minimally processed honeydew melons stored in air or controlled atmosphere. Postharvest Biology and Technology, v.14, p.351-357, 1998.

REDGWELL, R.J.; FISCHER, M. Fruit texture, cell wall metabolism and consumer perceptions. In: KNEE, M. (Ed). Fruit quality and its biological basis. Canada, 2002. Cap. 3, p.46-88.

SALUNKHE, D.K.; BOLIN, H.R.; REDDY, N.R. Storage, processing and nutritional quality of fruits and vegetables, Boca Raton: CRC Press, 1991.323p.

SANTOS, H.P. dos. Influência da sanificação sobre a qualidade de melão amarelo (Cucumis melo L.) minimamente processado. 2003, 80p. Dissertação (Mestrado em Ciência dos Alimentos) - Universidade Federal de Lavras, Lavras, MG.
SIGRIST, J.M.M.Transformações bioquímicas. In: BLEINROTH, E.W.; SIGRIST, J.M.M.; ARDITO, E.F.G.; CASTRO, J.V.; SPAGNOL, W.A.; NEVES FILHO, L.C. Tecnologia de pós-colheita de frutas tropicais. 2 ed. Campinas: ITAL, 1992. P. 33-40.

VILAS BOAS, E.V.B. Maturação pós-colheita de híbridos de tomate heterozigotos no loco alcobaça. 1998, 105p. Tese (Doutorado em Ciência dos Alimentos) Universidade Federal de Lavras, Lavras, MG.

WILEY, R.C. Minimally processed refrigerated fruits and vegetables, New York: Chapman \& Hall, 1994.368p.

WILLS, R. B. H; McGLASSON, W.B; GRAHAM, D.; JOYCE, D. Postharvest: an introduction to the physiology and handing of fruit, vegetables and ornamentals, 4 ed. Australia: New South Wales University Press, 1998. 262 p.

YAM, K.L.; LEE, D.S. Design of modified atmosphere packaging for fresh produce. In: ROONEY, M.L. Active Food Packaging, Glasgow: Chapman \& Hall, 1995. p.573.

ZAGORY, D.; KADER, A.A. Modified atmosphere packaging of fresh produce. Food Technology, v.42, n.9, p.70-77, 1988. 